recommendations were: Compliance with ISBAR, Location, Time taken, Start time, Staff attendance, Discussion of roles and responsibilities and Record keeping. The results prompted a re-audit. NCHD's were then given education sessions regarding the recommendation's. A summary of the recommendations was also placed in the clinical handover room. A re-audit was done 3 months later before change over.

2. patients were also randomly selected and were surveyed confidentially about Diagnosis, Investigations, Treatment plans and satisfactory communication to see if the team was complying with recommendation two in the NCG. Three months later, 30 patients were surveyed again.

Results It was found that:

\begin{tabular}{lll}
\hline \multicolumn{2}{l}{ Compliance $\%$ of recommendations set out by NCEC, HSE } & \\
\hline & Pre-intervention & Post intervention \\
ISBAR & $78 \%$ & $100 \%$ \\
Time taken at CH (15-30 mins) & $64 \%$ & $100 \%$ \\
CH start time (8.55am) & $73 \%$ & $100 \%$ \\
Role and responsibilities discussed at CH & $68 \%$ & $100 \%$ \\
All patients updated at CH (new and old) & $45 \%$ & $100 \%$ \\
Record keeping of handover list & $64 \%$ & $100 \%$ \\
Patients satisfactory communication & $83 \%$ & $97 \%$ \\
\hline
\end{tabular}

Conclusion Through educational sessions and teamwork a marked improvement was seen at handover after three months. Due to the changes implemented, handover became more efficient and also benefitted patients as the quality of care improved. The next step would be to start educating NCHDs at the beginning of each changeover so that handover continues to run smoothly.

\section{P168 THE PRIMARY AIM OF THIS STUDY IS TO IDENTIFY TOP CAUSES OF PAEDIATRIC EMERGENCY (PE) ATTENDANCES AND THEIR SEASONAL DISTRIBUTION}

Anwar Ayubi*. BHRUT, Romford, UK

\subsection{6/archdischild-2019-epa.523}

Methods In this observational hospital based study electronic data was analysed focusing on medical diagnosis and seasonal distribution over a period of 5 years (Sep 2013 to August 2018). Data was collected and analysed by the two authors. Excluded from the study neonates and those attended with non-medical conditions (e.g. injuries, surgical problems).

Results 32474 eligible patients attended the PE Department during the study period. Top medical diagnoses contributed to $65 \%(\mathrm{n}=21108)$ of total attendances and included fever without focus; $(n=3949 ; 12 \%)$; tonsillitis $(n=2485 ; 7.5 \%)$; gastritis and/or gastroenteritis $(\mathrm{n}=2971$; 9\%); acute bronchiolitis $(n=2042 ; 6 \%)$; bronchial asthma $(n=1602 ; 5 \%)$; upper respiratory tract infection $(n=1122 ; 3.5 \%)$; seizure $(2443$; $7.5 \%)$; skin rash $(\mathrm{n}=1772 ; 5.5 \%)$; sickle cell disease and other causes of anaemia $(n=2845 ; 9 \%)$. Seasonal distribution of most common medical diagnoses was autumn (29\%); summer (19\%); winter (27\%) and spring (25\%).

Conclusion Our findings showed convincing evidence that majority of medical diagnoses of PE attendance can be managed by an experienced general paediatricians and paediatric nurses. Furthermore, we found there was no considerable seasonal variation among these medical causes. .

\section{P169 AUDIT OF EPILEPSY PRACTICE IN A DISTRICT GENERAL HOSPITAL}

${ }^{1}$ Sairah Akbar*, ${ }^{2}$ Rosemary Grattan, ${ }^{2}$ Lesley Nairn. ${ }^{1}$ NHS Greater Glasgow and Clyde, Glasgow, UK; ${ }^{2}$ Greater Glasgow and Clyde, Glasgow, UK

\subsection{6/archdischild-2019-epa.524}

Epilepsy is a common disorder affecting 0.5 to $1 \%$ of the paediatric population. To improve patient outcomes and ensure provision of high-quality care, NICE have detailed quality standards in their 2013 document. ${ }^{1} \mathrm{~A}$ retrospective audit was carried out in 2018 in a district general hospital to review adherence to these standards. 104 patients were identified - 33 were under the care of a tertiary specialist with the remaining 71 looked after by General Pediatricians. This subgroup was included in further analysis. 54/71 were seen by Pediatricians with expertise in epilepsy with remaining 17 by General Pediatricians with no specific interest. Almost all patients (69/71) had contact with the Epilepsy Specialist Nurse; those that did not were looked after by non-experts in this field. 8 patients were appropriately referred to tertiary care with diagnostic challenge and lack of improvement on anti-epileptic medication being the commonest reason for referral. Almost all patients had a seizure classification (69/71) with this readily available in the notes in $79 \%$ of patients and all patients were appropriately imaged.

Our audit of practice in a district general has shown the standard of care provided to paediatric Epilepsy patients conforms well to national guidelines. Areas for improvement are to ensure ESN are involved in the care of these patients and use of the International League Against Epilepsy (ILAE) classification. $^{2}$

\section{REFERENCES}

1. Epilepsy in children and young people. NICE guidelines (2013)

2. The 2017 ILAE Classification of Seizures

\section{P170 A STUDY OF IRISH TRAINEE DOCTORS PRESCRIBING KNOWLEDGE FOR THE DIFFERENT MEDICATION OPTIONS FOR ADHD}

${ }^{1,2}$ Kate Irvine*, ${ }^{3,4}$ Professor Fiona McNicholas. 'St John of Gods Hospital, Dublin, Ireland; ${ }^{2}$ Irish College of Psychiatry, Dublin, Ireland; ${ }^{3}$ Our Lady's Children's Hospital, Dublin, Ireland; ${ }^{4}$ University College Dublin, Dublin, Ireland

\subsection{6/archdischild-2019-epa.525}

Introduction Attention-deficit/hyperactivity disorder (ADHD) is a common treatable childhood mental illness, with a prevalence of $7 \%$ in under 18 year olds. Functional impairment affects all environments and includes inattention impeding memory and learning, hyperactivity resulting in increased restlessness and movement, and impulsivity leading to poor judgement and risk taking behaviour. These impairments affect children's social inclusion and ability to integrate and enjoy life, but also their ability to fulfil important educational goals. Children and adolescents with ADHD are more likely to have co-morbid medical conditions, which in turn likely impacts on 